\title{
Role of the proximal and distal stomach in mixed solid and liquid meal emptying
}

\author{
P J Collins, L A Houghton, N W Read, M Horowitz, B E Chatterton, R Heddle, J Dent
}

\begin{abstract}
The role of the proximal and distal stomach in the emptying of solids and liquids from the stomach remains unclear. We have used a dual isotope technique to quantify proximal and distal stomach emptying of a solid (100 $\mathrm{g}$ of ${ }^{99 m}$ Tc labelled liver/ground beef) liquid (either $200 \mathrm{ml}$ of normal saline (eight subjects) or $25 \%$ dextrose (seven subjects) labelled with ${ }^{113 \mathrm{~m}}$ Indiethylenetriaminepenta-acetic acid) mixed meal. A manometric catheter simultaneously measured antral, pyloric, and duodenal motor activity. The liquid component dispersed rapidly throughout the stomach and emptied after a minimal lag period. The emptying of the $25 \%$ dextrose was delayed compared with the saline. This delay was associated with increased retention of the liquid in the distal stomach, a significant increase in localised phasic pyloric contractions, and a suppression of antral contractions. The solid component initially resided wholly within a proximal stomach reservoir area. Solids then redistributed from proximal to distal stomach during the emptying of liquid from the stomach. Dextrose delayed gastric emptying of solids compared with saline by increasing the solid lag period and retention in the proximal stomach. There was no significant difference between saline and dextrose meals in the distal stomach retention of solid or in the linear rate of emptying after the lag period. We conclude that, contrary to general opinion, the proximal stomach plays an important role in the control of gastric emptying of solids while the distal stomach is important in the emptying of nutrient liquids.
\end{abstract}

Departments of Nuclear Medicine, Medicine, and Gastroenterology, Royal Adelaide Hospital, Adelaide, South Australia

P J Collins

$M$ Horowitz

B E Chatterton

$R$ Heddle

J Dent

Subdepartment of Gastrointestina Physiology and Nutrition, Royal

Hallamshire Hospital, Sheffield

L A Houghton

N W Read

Correspondence to:

Mr P J Collins, Department of

Nuclear Medicine, Royal

Adelaide Hospital, Nort

Terrace, Adelaide 5000,

South Australia, Australia.

Accepted for publication

3 August 1990
The role of the gastric fundus and antrum in the emptying of solids and liquids remains contentious. Surgical resection of the canine fundus ${ }^{1}$ or vagal denervation of the proximal stomach ${ }^{2}$ has been shown to hasten liquid emptying but not to have any effect on solid emptying, while distal antrectomy ${ }^{3}$ or vagal denervation of the distal stomach $^{4}$ has been shown to accelerate solid emptying but not to effect liquid emptying. These observations led to the suggestion that it was the proximal stomach that regulated liquid emptying, while the distal stomach controlled solid emptying. Recent manometric and scintigraphic observations in man and dog, however, have shown that the emptying of solids is asociated with an initial relaxation of the proximal stomach, followed by a gradual increase in tonic contraction $^{5}$; while liquids empty in gushes associated with coordinated contractions involving the antrum and duodenum. ${ }^{67}$ These observations suggest that the proximal stomach does play a role in the emptying of solids, while the distal stomach is involved in the emptying of liquids.

The functions of the proximal and distal stomach in gastric emptying, however, may vary according to the nutrient content of the meal, since increasing the caloric content of the meal has been shown to delay gastric emptying ${ }^{89}$ and duodenal nutrients to relax the fundus, ${ }^{1011}$ suppress antral activity, ${ }^{12-14}$ and increase the phasic and tonic contractions of the pylorus. ${ }^{12} 1315$

This study aims to investigate the relative roles played by the proximal and distal stomach in the emptying of a mixed solid and liquid meal with either saline or dextrose as the liquid component, using a recently developed technique ${ }^{16}$ for discriminating between radioactivity in the proximal and distal regions of the stomach.

\section{Methods}

SUBJECTS

The studies were performed on 15 healthy asymptomatic volunteers ( 13 men, two women) aged between 18 and 51 years. Written informed consent was obtained in each case, and the study protocol was approved by the Research Review Committee of the Royal Adelaide Hospital.

\section{PROTOCOL}

After the subjects had fasted for at least 14 hours, a manometric catheter assembly incorporating three side holes in the antrum, four side holes in the duodenum, and a sleeve sensor to record pyloric activity was introduced through an anaesthetised nostril. ${ }^{6}$ When recordings of pressure and transmucosal potential difference indicated that the assembly was correctly positioned, ${ }^{6}$ the subject sat upright with his back against the detector of a gamma camera. Fasting manometric recordings were obtained for 30 minutes, after which the subject ate a solid meal consisting of $100 \mathrm{~g}$ cooked ground beef $(25 \mathrm{~g}$ protein, $21 \mathrm{~g}$ fat, energy content $=1230 \mathrm{~kJ}(270 \mathrm{kcal}))$ contain ing 37-55 MBq (1-1.5 mCi) of in vivo labelled ${ }^{99 m}$ Tc sulphur colloid-chicken liver. ${ }^{17}$ The 'liver burger' meal was ingested within five minutes and was immediately followed by a $200 \mathrm{ml}$ drink of either normal saline (eight subjects) or $25 \%$ dextrose in normal saline (seven subjects) (calorific value $=200 \mathrm{kcal}$, osmolality $=1775 \mathrm{mOsmol} /$ $\mathrm{kg}$ of $\mathrm{H}_{2} \mathrm{O}$ ). The drinks were labelled with 18-28 $\mathrm{MBq}(0.5-0.75 \mathrm{mCi})$ of ${ }^{113 \mathrm{~m}}$ In-labelled diethylenetriaminepenta-acetic acid (DTPA). As soon as the subjects began to ingest the food, images of the abdominal distribution of the two radionuclides were collected, at a rate of one frame every 30 seconds for the first 30 minutes and then at a rate of one frame every three minutes for at least two hours until the end of the 


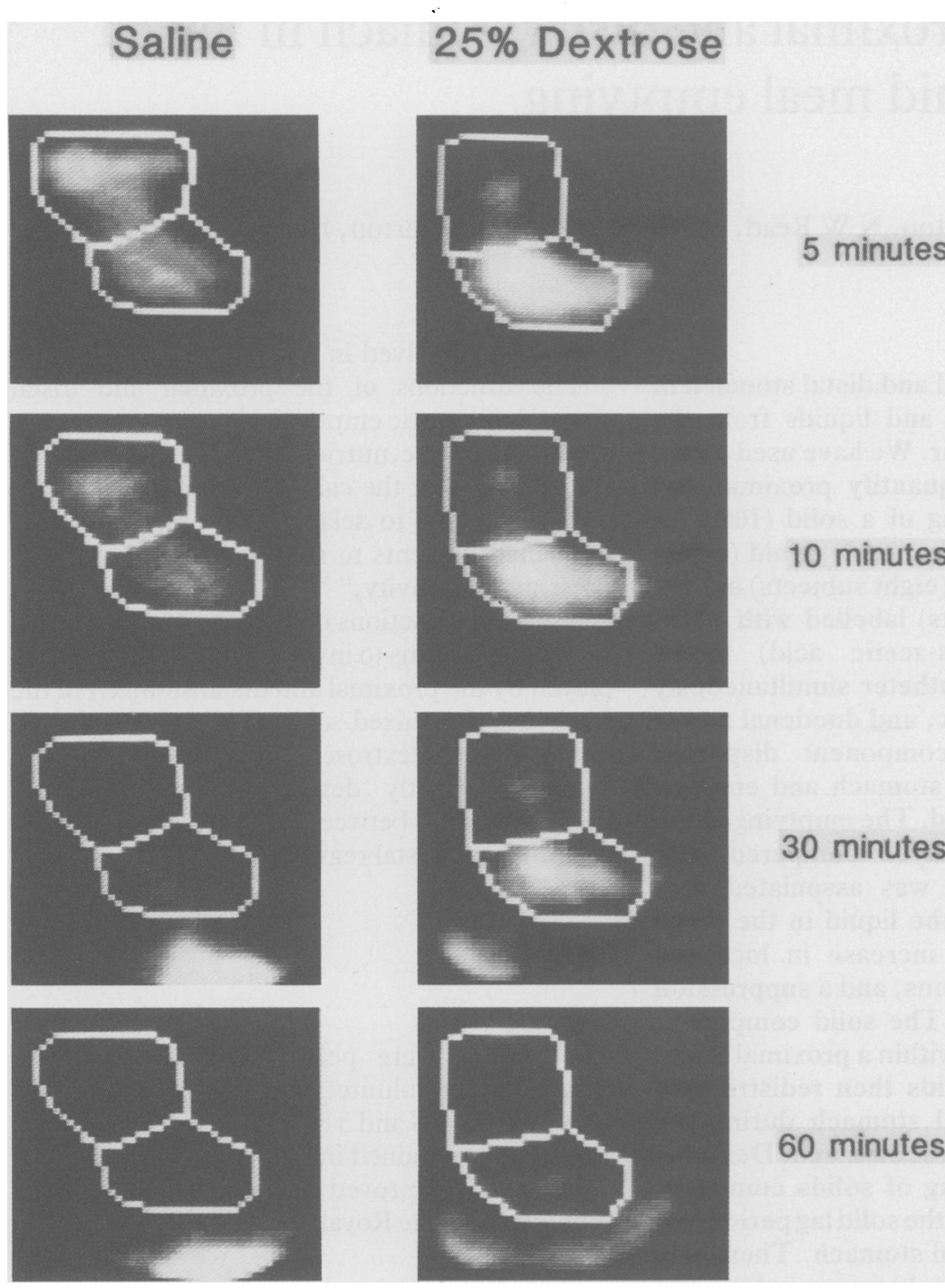

Figure 1: Scintiphotographs showing the distribution of the liquid component of a mixed solid/ liquid meal (left panel=saline, right panel $=25 \%$ dextrose) at 5, 10,30, and 60 minutes.

study. Data acquisition was interrupted briefly at 30 minute intervals to allow the subject to stand or sit away from the camera. At the end of data collection, $3 \cdot 7 \mathrm{MBq}(100 \mu \mathrm{Ci})$ of ${ }^{99} \mathrm{Tc}$-labelled DTPA in $150 \mathrm{ml}$ water was given orally and a one minute left lateral image of the upper abdomen was taken.

\section{ANALYSIS OF GASTRIC EMPTYING}

Gastric emptying of the solid and liquid phases of the meal was monitored simultaneously using a scintillation camera (Nuclear Chicago, Phogamma III) that was linked to a dedicated minicomputer (PDP11/34, Digital Equipment Corporation). Data were corrected for patient movement, radionuclide decay, Compton scatter, and gamma ray attenuation using the lateral image method. ${ }^{918}$ Time zero was defined as the time of meal completion. The determination of regions of interest (ROI) for the proximal, distal, and total stomach has been described previously. ${ }^{16}$ The proximal stomach region was defined as the 'reservoir' area seen in all subjects for at least the first few minutes after ingestion of the solid meal and a proximal/distal stomach dividing line was drawn immediately below this

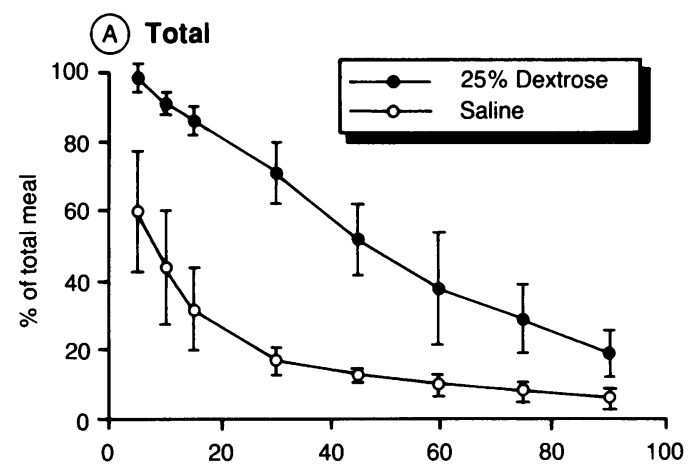

(B) Proximal

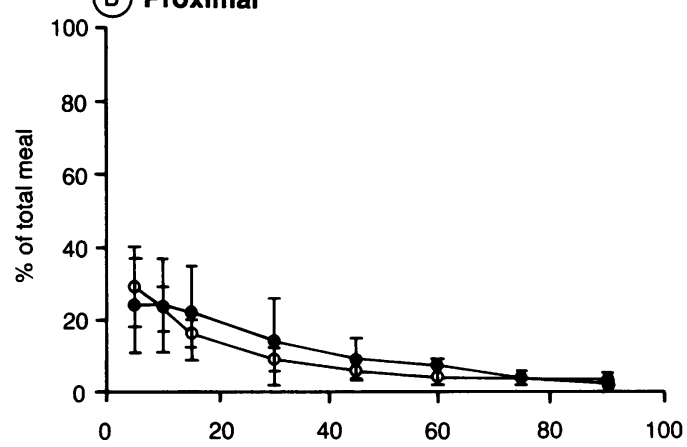

(C) Distal

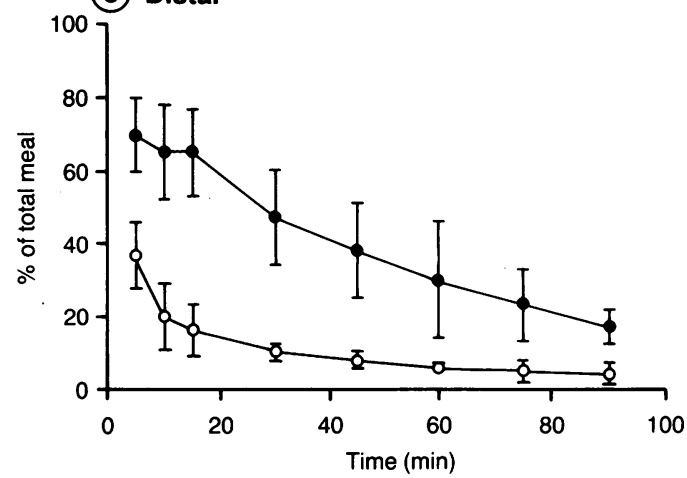

Figure 2: Composite total $(A)$, proximal (B), and distal stomach $(C)$ emptying curves of the liquid component of $a$ mixed solid/liquid meal (saline $(\mathrm{O}), 25 \%$ dextrose $(\mathrm{O})$ ). The data are median values (interquartile range).

region. For each of the three ROIs (proximal, distal, and total stomach), activity time curves, expressed as a percentage of total meal against time, were derived. The count rate at the end of the lag period (the frame preceding that in which activity appeared in the proximal small intestine)

TABLE I Effect of increasing the liquid calorie content of a mixed solid/liquid meal on liquid emptying. (Values median (range))

\begin{tabular}{|c|c|c|c|}
\hline & $\begin{array}{l}\text { Normal } \\
\text { saline }\end{array}$ & $\begin{array}{l}25 \% \\
\text { dextrose }\end{array}$ & $p$ \\
\hline \multicolumn{4}{|l|}{ Total stomach: } \\
\hline $\begin{array}{l}\text { Lag period }(\mathrm{min}) \\
\text { Retention at } 10 \mathrm{~min} \\
(\%)\end{array}$ & $\begin{array}{r}1(0 \cdot 5-3) \\
44(24-86)\end{array}$ & $\begin{array}{l}6(3-7) \\
91(86-93)\end{array}$ & $\begin{array}{l}\mathrm{p}<0.01 \\
\mathrm{p}<0.01\end{array}$ \\
\hline $\begin{array}{l}\text { Retention at } 60 \mathrm{~min} \\
(\%)\end{array}$ & $10(4-16)$ & $38(16-59)$ & $\mathrm{p}<0.01$ \\
\hline \multicolumn{4}{|l|}{ Proximal stomach: } \\
\hline $\begin{array}{l}\text { Retention at } 10 \mathrm{~min} \\
(\%)\end{array}$ & $23(8-32)$ & $24(12-52)$ & \\
\hline Retention at $30 \mathrm{~min}$ & $9(3-13)$ & $14(8-35)$ & \\
\hline $\begin{array}{l}\text { Distal stomach: } \\
\text { Retention at } 10 \mathrm{~min}\end{array}$ & $20(13-63)$ & $65(40-81)$ & $\mathrm{p}<0.01$ \\
\hline Retention at $30 \mathrm{~min}$ & $10(7-31)$ & $47(28-74)$ & $\mathrm{p}<0.01$ \\
\hline Maximum content (\%) & $41(27-72)$ & $72(46-88)$ & $\mathrm{p}<0.02$ \\
\hline
\end{tabular}




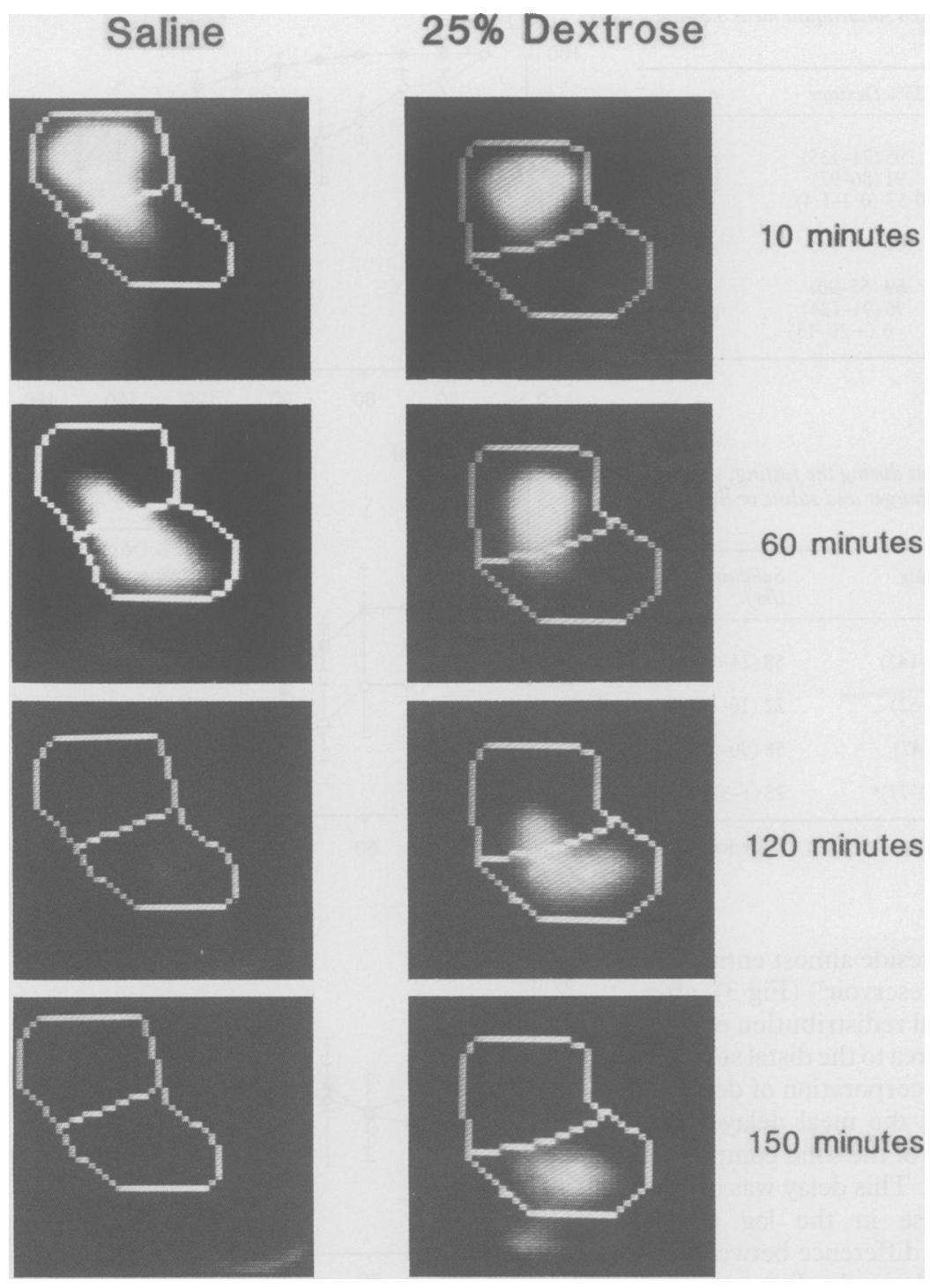

Figure 3: Scintiphotographs showing the distribution of the solid component of a mixed solid/ liquid meal (left panel $=$ saline, right panel $=25 \%$ dextrose) at 10,60,120, and 150 minutes.

was used to determine the value for $100 \%$ retention. ${ }^{16}$ Various emptying parameters were derived from these curves.

\section{Solid meal}

For the total stomach, these parameters were the lag period before food entered the duodenum (SLP) (as observed on the computer images), the percentage of the meal remaining (retention) at 120 minutes after meal completion, and the linear emptying rate after the lag period. For the proximal stomach, the parameter retention at $\mathbf{6 0}$ minutes was derived, and for the distal stomach, the maximum content expressed as a percentage of the total meal (SMC) and the time to reach $90 \%$ of SMC $\left(\mathrm{ST}_{90}\right)$. The parameter SLP-ST ${ }_{90}$ was used as an index of the average retention time of solid food in the distal region.

\section{Liquid meal}

For the total stomach, the lag period and the percentage retention at 10 and 60 minutes were obtained. For the proximal and distal stomach, the amount of the meal remaining at 10 and 30 minutes was measured as well as the maximum distal stomach content (\%).

\section{ANALYSIS OF MANOMETRY}

The criteria used to analyse the manometric data have been described previously. ${ }^{615}$ The manometric results have been reported in detail in a previous publication. ${ }^{15}$ A coordinated pressure wave was defined as a single contraction or cluster of two to eight contractions occurring within $\mathbf{1 0}$ seconds in at least three separate but not necessarily adjacent channels, and separated by quiescence lasting at least 20 seconds. Propagation of a pressure wave in an aboral direction was said to take place when the leading edge of the wave complex occurred $>1$ second but $<5$ seconds after a similar wave in the adjacent aboral recording site. Isolated pyloric pressure waves (IPPWs) were defined as pressure waves recorded by the sleeve sensor in the absence of pressure waves recorded by the adjacent antral and duodenal sideholes within 10 seconds of the peak of the pyloric wave.

\section{STATISTICAL METHODS}

Data were evaluated using the Wilcoxon rank sum test.

\section{Results}

\section{GASTRIC EMPTYING}

Curves for the proximal, distal, and total stomach were obtained in 14 of the 15 subjects. In one subject (saline group) it was not possible to segment the stomach into proximal and distal subregions because of a non-typical profile (small, round stomach) and only total stomach data were included in the subsequent analysis.

\section{Liquid emptying}

After ingestion, liquid was rapidly dispersed through the whole stomach and there was a minimal lag period before stomach emptying began (Fig 1). The pattern of liquid emptying for saline was non-linear with a slope that decreased with time; dextrose emptied in an approximately linear fashion. The liquid lag period was longer for dextrose $(p<0.01)$ and there was greater retention of liquid at 10 minutes and 60 minutes (Fig 1, Fig 2A, Table I). The slower emptying of dextrose was associated with a significant increase in the amount of liquid in the distal stomach (Fig 1, Fig 2C, Table I) at 10 and 30 minutes $(\mathrm{p}<0.01)$ and in the maximum distal stomach content $(p<0.02)$. In comparison there was no significant difference in the emptying rate of saline or dextrose from the proximal stomach. (Table I).

\section{Solid emptying}

Solid emptying from the total stomach was slower than liquid emptying and was characterised by an initial lag period, followed by an emptying phase which approximated to a linear pattern. Directly after ingestion, the solid com- 
TABLE II Effect of increasing the liquid calorie content of a mixed solid/liquid meal on solid emptying. (Values, mean (range))

\begin{tabular}{lccc}
\hline & Normal saline & $25 \%$ Dextrose & $p$ \\
\hline Total stomach: & & & \\
Lag period (min) (SLP) & $37(15-140)$ & $95(71-135)$ & $\mathrm{p}<0.02$ \\
Retention at 120 min (\%) & $36(3-84)$ & $91(86-97)$ & $\mathrm{p}<0.01$ \\
$\quad$ Linear emptying rate (\%/min) & $0.68(0.4-1 \cdot 5)$ & $0.57(0.2-1 \cdot 4)$ & \\
Proximal stomach: & $38(16-54)$ & $61(40-92)$ & $\mathrm{p}<0.02$ \\
$\quad$ Retention at 60 min (\%) & $65(23-79)$ & $69(55-90)$ & \\
Distal stomach: & $35(20-76)$ & $96(91-124)$ & $\mathrm{p}<0.01$ \\
$\quad$ Maximum content (\%) (SMC) & $13(-11-15)$ & $0(-20-13)$ & \\
Time to 90\% of SMC (min)(ST S $\left._{90}\right)$ & & & \\
SLP-ST $_{90}$ & & & \\
\hline
\end{tabular}

SLP=stomach lag period; SMC= distal stomach maximal content.

TABLE III Comparison of the rate of occurrence of motor patterns during the fasting, solid lag, and solid emptying periods after ingestion of either the liver burger and saline or liver burger and dextrose mixed meal. (Values, median (range))

\begin{tabular}{lccl}
\hline & $\begin{array}{l}\text { Fasting } \\
(/ \mathrm{hr})\end{array}$ & $\begin{array}{l}\text { Solid lag } \\
(/ \mathrm{hr})\end{array}$ & $\begin{array}{l}\text { Solid emptying } \\
(/ \mathrm{hr})\end{array}$ \\
\hline $\begin{array}{l}\text { Liver burger/saline meal: } \\
\text { Coordinated pressure waves involving } \\
\text { antrum }\end{array}$ & $0(0-60)$ & $39(0-142)$ & $58(24-147)$ \\
$\begin{array}{c}\text { Isolated pyloric pressure waves } \\
\text { Liver burger/dextrose meal: }\end{array}$ & $0(0-44)$ & $7(0-52)$ & $22(10-64)^{\star}$ \\
$\begin{array}{c}\text { Coordinated pressure waves involving } \\
\text { antrum }\end{array}$ & $27(0-67)$ & $16(8-47)$ & $58(30-144)^{\star} \dagger$ \\
Isolated pyloric pressure waves & $0(0-14)$ & $58(30-77)^{\star}$ & $23(1-37)^{\star} \dagger$ \\
\hline
\end{tabular}

$\star$ Statistically significant difference from fasting $(p<0.05)$; †statistically significant difference from solid lag period $(p<0.05)$

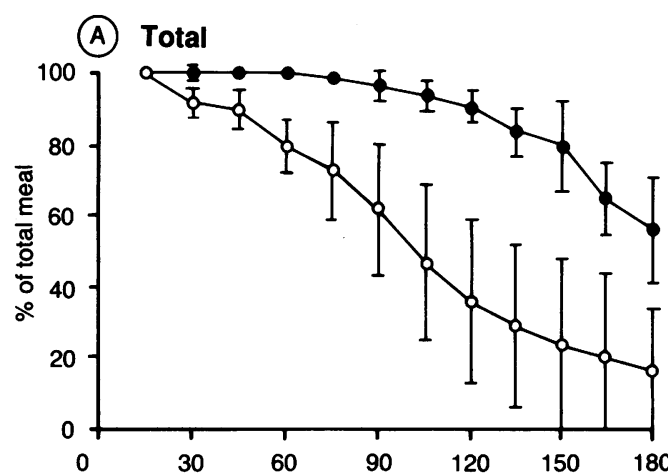

(B) Proximal

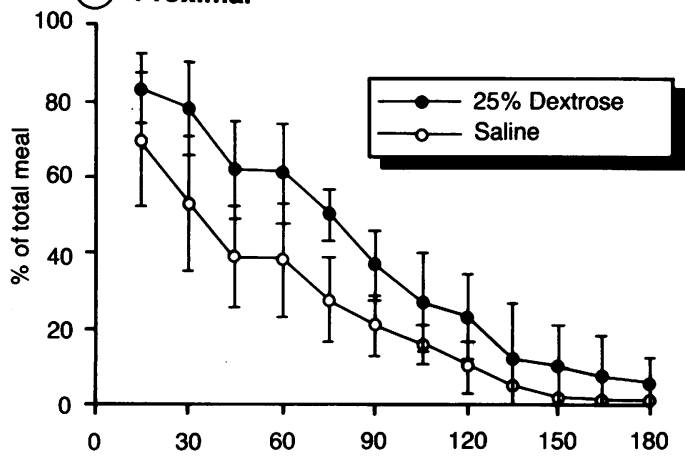

(C) Distal

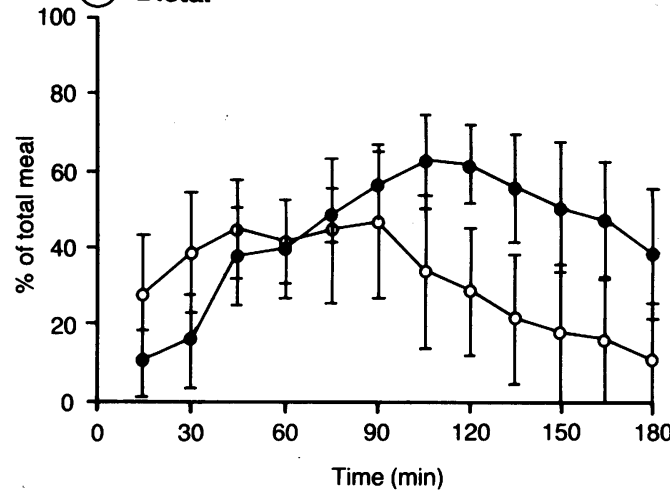

Figure 4: Composite total (A), proximal (B), and distal stomach $(C)$ emptying curves of the solid component of a mixed solidlliquid meal (saline $(\mathrm{O}), 25 \%$ dextrose $(\mathbf{O}))$. The data are median (interquartile range).

during the fasting period and during the solid lag period of the saline and burger mixed meal $(p<0.05)$. As with the saline and burger meal, the onset of solid emptying was associated with an increase in coordinated pressure waves involving the antrum, but with a significant decline in the occurrence of IPPWs.

\section{Discussion}

This study shows that the distribution of liquid in the human stomach differs noticeably from solids when both are fed in a mixed solid and liquid meal. On ingestion, liquids rapidly dispersed throughout the stomach with no evidence of preferential storage in the proximal stomach (Fig 1), whereas the solid component resided almost entirely in the proximal stomach reservoir and was then gradually redistributed to the distal stomach during the lag phase as the liquid emptied. The solid then emptied linearly from the stomach.

Why do solids not redistribute in the same way as liquids? What is responsible for retention of 
solids in the fundus? The striking discrimination between the two phases strongly suggests the presence of a physical barrier that prevents the access of solids into a distal component but allows passage of liquids. We and others ${ }^{1619}$ have observed a mid-gastric transverse band and argued that it may play an important role in the redistribution and emptying of solid food from the stomach. It seems likely that a mid-gastric contraction band is responsible for this type of solid/liquid discrimination.

The incorporation of dextrose into the liquid phase of a mixed solid and liquid meal delays gastric emptying of that phase. Dextrose seemed to be retained largely in the distal stomach. These data do not altogether support the concept that the fundus is primarily responsible for controlling the rate of emptying of liquids and suggest instead a major role for the gastric antrum. The manometric data suggests that suppression of antral activity and the increased phasic pyloric activity could account for the pooling of the dextrose in the antrum.

The delay and pooling of dextrose in the antrum was associated with a corresponding delay in emptying of solids because of a slower redistribution from proximal to distal stomach, with no significant increase in either the antral residence time or the linear rate of emptying. These data support our previous finding ${ }^{16}$ that redistribution is a major component of the lag period, and suggest that the gastric fundus has an important role to play in the emptying of solids. What might this role be? One possibility is that contraction of the fundus primes the antral pump, pressing solid material down into the antrum to be gradually disrupted by antral contractions until particles are small enough to pass through the pylorus. The interaction of dextrose with duodenal receptors would be expected to relax the fundus, tending to alter the balance of forces in favour of proximal stomach retention.

In conclusion, this study has shown that the proximal stomach may play a more important role in the emptying of solids, and the distal stomach a more important role in the emptying of liquids, than had previously been recognised.

1 Wilbur BG, Kelly KA, Code CF. Effect of gastric fundectomy on canine gastric electrical and motor activity. Am $\mathcal{F}$ Physiol 1974; 226: 1445-9.

2 Wilbur BG, Kelly KA. Effect of proximal gastric, complete gastric and truncal vagotomy on canine gastric electric activity, motility and emptying. Ann Surg 1973; 178: 295303.

3 Dozois RR, Kelly KA, Code CF. Effect of distal antrectomy on gastric emptying of liquids and solids. Gastroenterology 1971; 61: 675-81.

$4 \mathrm{Mroz}$ CT, Kelly KA. The role of the extrinsic antral nerves in the regulation of gastric emptying. Surg Gynecol Obstet 1977; 145: 369-77.

5 Azpiroz F, Malagelada JR. Physiological variations in canine gastric tone measured by an electronic barostat. Am $\mathcal{f}$ Physiol 1985; 248: G229-37.

6 Houghton LA, Read NW, Heddle R, et al. Motor activity of the gastric antrum, pylorus and duodenum under fasted conditions and after a liquid meal. Gastroenterology 1988; 94: 1276-84.

7 Prove J, Ehrlein HJ. Motor function of gastric antrum and pylorus for evacuation of low and high viscosity meals in dogs. Gut 1982; 23: 150-6.

8 Hunt JN, Knox MT. Regulation of gastric emptying. In: Code CF, Hendel W, eds. Handbook of physiology. Section 6, Vol 4. Alimentary Canal. Washington DC: American Physiology Alimentary Canal. Wash.

9 Collins PJ, Horowitz M, Cook DJ, Harding PE, Shearman DJC. Gastric emptying in normal subjects - a reproducible technique using a single scintillation camera and computer system. Gut 1983; 24: 1117-25.

10 Dooley CP, Reznick JB, Valenzuela JE. Variations in gastric and duodenal motility during gastric emptying of liquid meals in humans. Gastroenterology 1984; 87: 1114-9.

11 Azpiroz F, Malagelada JR. Intestinal control of gastric tone. Am F Physiol 1985; 249: G501-9.

12 Heddle R, Fone D, Dent J, Horowitz M. Stimulation of pyloric motility by intraduodenal dextrose in normal subpyloric motility by intraduoder

13 Heddle R, Dent J, Read NW, et al. Antropyloroduodenal motor responses to intraduodenal lipid infusion in healthy motor responses to intraduodenal lipid infusion
volunteers. Am F Physiol 1988; 254: G671-9.

14 White CM, Poxon V, Alexander-Williams J. Effects of nutrient liquids on human gastroduodenal motor activity. Gut 1983; 24: 1109-16.

15 Houghton LA, Read NW, Heddle R, et al. Relationship of the motor activity of the antrum, pylorus and duodenum to gastric emptying of a solid-liquid mixed meal. Gastroenterology 1988; 94: 1285-91.

16 Collins PJ, Horowitz M, Chatterton BE. Proximal, distal and total stomach emptying of a digestible solid meal in normal subjects. Br $\mathcal{F}$ Radiol 1988; 61: 12-8.

17 Meyer JH, MacGregor IL, Gueller R, Marti P, Cavalieri R. Meyer JH, MacGregor IL, Gueller R, Marti P, Cavalieri R.
${ }_{9 m}$ T-tagged chicken liver as a marker of solid food in the human stomach. Dig Dis 197.6; 21: 296-304.

18 Collins PJ, Horowitz M, Shearman DJC, Chatterton BE. Correction for tissue attenuation in radionuclide gastric emptying studies: a comparison of a lateral image method and a geometric mean method. Br $\mathcal{Y}$ Radiol 1984; 57: 689-95.

19 Moore JG, Dubois A, Christian PE, Elgin D, Alazraki N. Evidence for a midgastric transverse band in humans. Gastroenterology 1986; 91: 540-5. 